\section{La hipótesis de Brenner sobre la economía y la salud}

La literatura sobre la salud pública muestra que el desempleo produce estrés y eleva las tasas de suicidio y de morbilidad y mortalidad por enfermedad cardiovascular y cáncer de pulmón. En 1979, MH Brenner dio a conocer una hipótesis sobre los ciclos económicos y la salud basada en el análisis de una serie temporal de 1936 a 1976 sobre la relación entre las tasas de mortalidad agregada y varias medidas de actividad económica en Inglaterra y Gales. Sus resultados indicaban que los cambios económicos caracterizados por el desempleo y por fluctuaciones del ingreso per cápita pueden tener profundas consecuencias adversas en la salud de las poblaciones. Esa variabilidad, declaró, se relaciona directamente con el riesgo de mortalidad. A su ver, los ciclos económicos tienden a empeorar el gradiente socioeconómico de la salud porque su efecto más perjudicial se manifiesta en los grupos de menores ingresos. Brenner alegaba que cuando la economía es inestable, la inseguridad resultante suele dar lugar a hábitos de vida también inestables, se deterioran las redes sociales básicas y las angustias vitales se sienten hondamente; es decir, que la relativa falta de seguridad económica y laboral de los grupos de menos ingresos explica en gran medida sus altas tasas de mortalidad. En esos grupos, el estrés y la falta de adiestramiento en nuevas formas de trabajo coartan la capacidad para adaptarse a los cambios del ambiente económico.

Los trabajadores no calificados y los semicalificados en industrias cíclicas son los primeros en perder sus empleos al principio de las recesiones y los que más suelen tardar en conseguir nuevos trabajos cuando la economía se recupera. Además, muchos pierden su empleo debido a cambios estructurales, por ejemplo, cuando se renueva la tecnología. En este caso, los no calificados no encuentran oportunidades de empleo aunque la economía haya mejorado. Esto equivale a decir que el efecto negativo producido por un bajón en la economía tiene más peso que las mejoras de salud logradas con la recuperación económica. Así, la fluctuación negativa de los ingresos presupone un riesgo más alto de mortalidad durante una recesión.

Varios estudios ulteriores destacan los puntos flacos del modelo con resultados que por lo general contradicen los de Brenner, pero por su parte con- tienen otros errores o no son estrictamente comparables. En uno de los análisis más recientes sobre el trabajo de Brenner, A. Laporte dice que los investigadores anteriores dieron por sentada la estacionariedad de los datos sobre mortalidad y economía sin tener en cuenta su naturaleza de serie temporal. Su propio trabajo analiza el impacto de los ciclos económicos sobre la mortalidad agregada y ajustada por edad en los Estados Unidos de América, de 1948 a 1996, teniendo en cuenta que constituyen series temporales. Como variables explicatorias se incluyen el desempleo como porcentaje de la fuerza de trabajo, el producto interno bruto (PIB) real per cápita y el gasto total real en salud per cápita.

Según los resultados de Laporte, solo el desempleo mostró una asociación significativa a corto plazo: el aumento de un punto porcentual del desempleo se asoció a una reducción de la mortalidad agregada de alrededor de 10 muertes por 100000 . Ni los ingresos ni los gastos en salud parecieron tener efecto alguno sobre la mortalidad. Sin embargo, el PIB per cápita mostró una asociación significativa a largo plazo, quizá porque en los Estados Unidos la calidad de la atención médica depende de la capacidad para pagarla. En cuanto al desempleo, los resultados no apoyaron la tesis de Brenner sobre el daño que causan las fluctuaciones del ciclo económico. Más bien parecen apoyar a otros investigadores cuyos resultados indican que el desempleo es bueno para la salud. Uno de ellos se refirió al hecho de que en los Estados Unidos muchos desempleados tienen el derecho de recibir una compensación, lo cual beneficia su salud. Según Laporte, el desempleo se asoció a una disminución de la mortalidad a corto y largo plazo. Es de considerar que quizá la tasa de desempleo medida no sea un buen indicador de la experiencia individual con el desempleo y el estrés que acarrea. Si afecta a personas que tienen buenas probabilidades de hallar otro empleo o que trabajan en industrias cíclicas y ahorran para las épocas sin empleo, el aumento en la tasa de desempleo no necesariamente significa un incremento del estrés. Cuando la tasa de desempleo se reduce de nuevo, las personas que no han logrado hallar trabajo, especialmente si ha transcurrido mucho tiempo sin hallarlo, sufren de gran estrés y depresión. En este caso, se observa una coincidencia entre la intensidad del estrés asociado con el desempleo y la disminución de la tasa.

$\mathrm{Al}$ igual que otros estudios anteriores, el de Laporte pone a prueba la hipótesis de Brenner con 
datos de un país industrializado. Aunque la misma curva convexa básica de mortalidad e ingreso se aplique tanto a los países en desarrollo como a los desarrollados, es de esperar que el efecto de las fluctuaciones económicas en la mortalidad se manifieste más fuertemente en los países más pobres. De igual modo es de esperar que el efecto del desempleo, cualquiera que sea el ingreso promedio, se sienta más en países que carecen de seguros por desempleo.

Laporte opina que la principal falla del trabajo de Brenner consiste en no haber tenido en cuenta las características de serie temporal de los datos de nivel macro. Sus resultados indican que los ciclos económicos sí tienen un efecto permanente en la salud de las poblaciones. Paradójicamente, también apuntan a que el crecimiento económico y el aumento del desempleo reducen el riesgo de mortalidad agregado. El que sus resultados no coincidan con los de Brenner no debe traducirse en un rechazo de la hipótesis brenneriana, ya que el argumento original tenía que ver con los efectos de las fluctuaciones económicas en los segmentos más pobres de la sociedad. Bien puede ser que los efectos de los cambios en el ingreso de las personas situadas al pie de la escala distributiva sean muy significativos en función del riesgo de mortalidad. La falta de coincidencia entre Brenner y Laporte quizá se deba a que las medidas de fluctuación económica comúnmente usadas no son sensibles a los efectos de esos ciclos en los grupos de mayor riego. (Laporte A. Do economic cycles have a permanent effect on population health? Revisiting the Brenner hypothesis. Health Econ. 2004;13: 767-79.)

\section{Variabilidad genética del virus de la fiebre amarilla en Brasil}

El virus de la fiebre amarilla (VFA) se transmite por la picadura de mosquitos infectados y produce fiebre hemorrágica grave en las personas. A pesar de existir una vacuna eficaz y segura, la fiebre amarilla aún constituye un problema de salud pública en las áreas tropicales de África y América del Sur. El rápido aumento de casos de esta enfermedad en Brasil y la reinfestación de zonas urbanas con su vector, el mosquito Aedes aegypti, han obligado a desplegar todos los recursos existentes para el control y la vigilancia de esta infección. Durante el año 2000 ocurrieron casos de fiebre amarilla en los alrededores de Brasilia, la capital de Brasil, y en 2001 el VFA se extendió a áreas de Minas Gerais donde hasta el momento no se había registrado su presencia.

En América del Sur, el VFA se mantiene en ciclos enzoóticos en los que intervienen monos y mosquitos de los géneros Haemagogus y Sabethes, propios de los bosques de sombra. En Brasil se han definido tres zonas geográficas en las que circula el VFA: la región endémica, en la que el virus se mantiene en una población móvil de monos y los casos en humanos son pocos y esporádicos; la zona de transición de emergencia, en la que es frecuente el contacto entre las personas y los monos y abundan los mosquitos infectados; y la región epidémica, en la que hay grandes concentraciones de personas y una alta densidad de mosquitos capaces de transmitir la infección, por lo que existe la posibilidad de que aparezcan grandes brotes urbanos de fiebre amarilla.

En este trabajo se estudió la diversidad genética de 79 cepas de VFA aisladas en Brasil entre 1954 y 2001, y se examinó la distribución geográfica de las variantes genéticas con vistas a determinar los patrones de divergencia y la dispersión viral en cinco regiones del país. Las regiones estudiadas fueron: la región amazónica septentrional, la región nororiental (muy seca), la región centrooccidental (pantanos y sabanas), la región sudoriental (la más densamente poblada, con un amplio sistema de carreteras y ferrocarriles) y la región meridional limítrofe con Argentina y Paraguay (la zona más templada).

Se investigaron las características específicas de las 79 cepas estudiadas (ubicación geográfica, fuente de aislamiento, pasos de cultivo y evolución clínica en los casos de infección en humanos). Todas las cepas fueron aisladas inicialmente en ratones lactantes y cultivadas en células C6/36 para crear un banco de cepas en el Instituto Evandro Chagas, en Belém, Brasil. De las cepas virales, 38 (48\%) procedían de personas (24 de ellas, de pacientes fallecidos); 7 (9\%) de monos; y 34 (43\%) de mosquitos, principalmente $H$. janthinomys. Los aislamientos abarcaban un período de 67 años y 12 estados: Amapá (1 aislamiento), Bahia (1 aislamiento), Distrito Federal (1 aislamiento), Goiás (10 aislamientos), Maranhão (6 aislamientos), Minas Gerais (7 aislamientos), Mato Grosso (4 aislamientos), Mato Grosso do Sul (5 aislamientos), Pará (39 aislamientos), Rondônia (2 aislamientos), Roraima (1 aislamiento) y Tocantins (2 aislamientos).

Para el análisis filogenético se extrajo ARN viral y se amplificó mediante los procedimientos de transcripción inversa y reacción en cadena de la polimerasa. El segmento amplificado contenía 595 pares de bases (255 nucleótidos de la región NS5 y 340 de la región no codificante del extremo 3'). Los segmentos nucleotídicos amplificados se secuenciaron y alinearon en busca de mutaciones.

Las cepas de VFA estudiadas pertenecían al genotipo sudamericano I, con la excepción de una cepa aislada en Rondônia que pertenecía al genotipo sudamericano II. 